\title{
Nueva interpretación de un mosaico de la Colonia Patricia Corduba
}

\author{
Ma Pilar San Nicolás Pedraz
}

\begin{abstract}
RESUMEN
ABSTRACT

Se valora de nuevo un mosaico de la A mosaic of the Patricia Corduba colonia Patricia Corduba con la representación del águila sobre un globo terrestre, como alusión a Júpiter, un unicum en cuanto a su iconografía en la musivaria hispano-romana.

\author{
PALABRAS CLAVE \\ Mosaico, colonica Patricia Corduba, \\ águila, Júpiter, iconografía
} colony is assessed again. An eagle over the earth globe representing the god Jupiter, constitutes an unicum in teh hispano-roman musivaria iconography.

\section{KEY WORDS}

Mosaic, Musivaria, iconography, eagle, Jupiter, Patricia Corduba colony.
\end{abstract}

Hace algunos años, dentro de los últimos hallazgos de mosaicos romanos en Hispania (1977-1987), publicamos un pavimento descubierto durante las labores de cimentación de un edificio de una plaza de Córdoba que no fue valorado adecuadamente ${ }^{1}$, por lo que hemos estimado conveniente hacerlo ahora por ser un unicum en cuanto a su temática en la musivaria hispanorromana.

El mosaico está enmarcado por una línea de peltas verticales, afrontadas a cada lado de un cuadrado sobre la punta ${ }^{2}$. Ocho cuadros en torno a un gran medallón central, bordeados por una trenza, forman el campo del mosaico; en el interior de estos cuadros se hallan representados distintas aves. En el medallón central aparece majestuosamente un águila sobre el globo terráqueo (Figs. 1 y 2). El esquema compositivo puede encuadrarse

J. M. BlÁzouez et alii, Hallazgos de mosaicos romanos en Hispania (1977-1987), Espacio, Tiempo y Forma 6, Serie II, 1993, 254-255, fig. 25.

2 C. Balmelle et alii, Le Décor Géométrique de la Mosaïque Romaine, Paris 1985, fig. 59a. 
en «Bandkrenzgeflecht III, Zentralkcomposition» de Jalies, que se docu-

menta desde mediados del siglo II hasta el $\mathrm{VI}^{3}$.

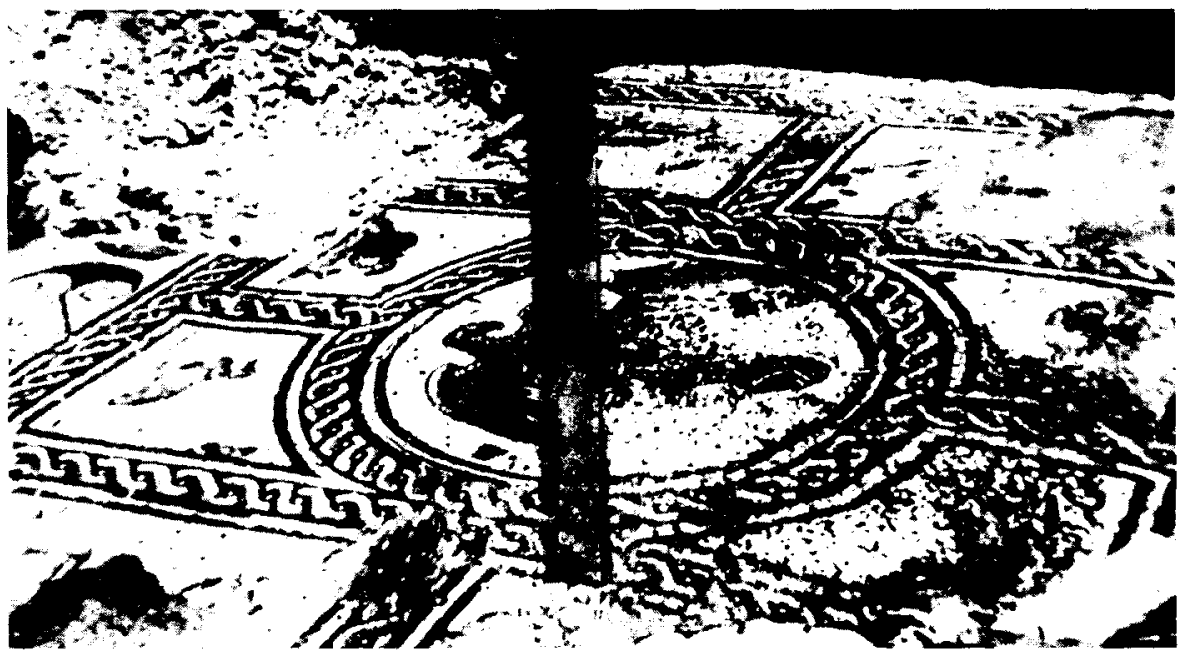

Figura 1. Mosaico de la Colonia Patricia Corduba.

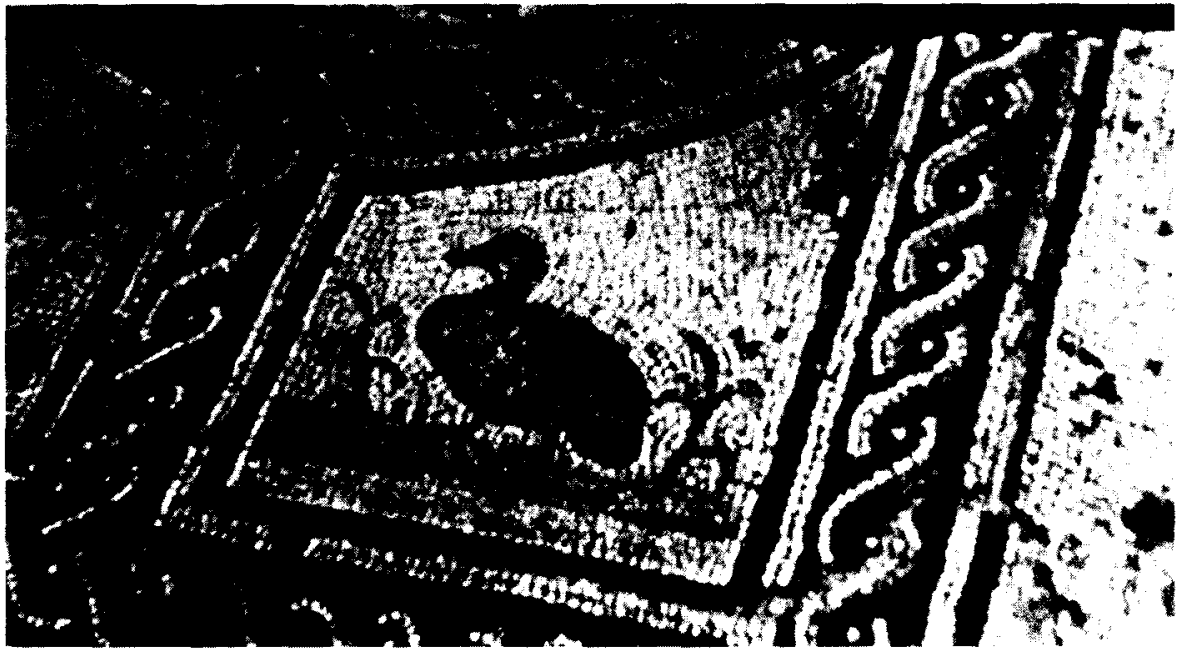

Figura 2. Detalle del mosaico cordobés con la representación de un pato.

G. SALIES, Untersuchunger zu den geometrischen Gliederungsschemata römischer Mosaiken, BJ. 174, 1974, 5, Bild 1, 12. 
Evidentemente el águila es la suprema ave de Zeus/ Júpiter, que le .... Jnsó en suerte cuando los dioses se repartieron las aves o como señala Higino (Astron. II 16) fue el propio dios quién la eligió; su vuelo era consıderado por algunos mitógrafos como presagio enviado por la divinidad (Paus. 1 32, 2; Eurip. Ion. 298; Estr. IX 2, 11). Su imagen aparece ampliamente documentada, como símbolo de Zeus, en las monedas de Susa y Seleucia, datadas en los siglos II a.C. hasta el I d.C. ${ }^{4}$, que constituyen el vehículo de difusión de la iconografía de Zeus/ Júpiter en el Imperio. El globo terráqueo es otro de los principales atributos del dios, aludiendo al concepto en el que le tenían los griegos como padre del mundo (Hom. lía. XV 187-224), preocupado de mantener en él el orden y la justicia. En el mundo romano fue invocado con el solemne epíteto Conservator Orbis, como aparece en las monedas e inscripciones de época imperial, que guarda relación con esta función.

Las imágenes del dios son innumerables en el arte antiguo, generalmente se le representa con rasgos de hombre maduro, barbado, de robusta complexión y con expresión de serena majestad como suprema divinidad. Raramente aparece completamente desnudo, excepto en las representaciones más antiguas; suele llevar un largo manto, que deja al descubierto el brazo derecho y el pecho. Entre sus atributos aparecen con diferentes variaciones iconográficas, el rayo, el cetro, la Victoria, el globo y el águila ${ }^{5}$.

La musivaria romana ha proporcionado varias imágenes de esta divinidad, aunque con diferente simbología. Baste recordar el gran mosaico de la villa bajo-imperial de La Malena en Azuara (Zaragoza), en el que el dios, coronado y portando el cetro, preside, junto con otras seis divinidades, las bodas de Cadmo y Harmonia ${ }^{6}$; los pavimentos de sus amores con mortales, como el de Ouled Agla (Argelia), de finales del siglo III o de principios del IV, que se conserva en el Museo de Constantina ${ }^{7}$, en el que Júpiter aparece sentado recibiendo la copa que le entrega Ganímedes

4 El águila con las alas abiertas aparece en varios ejemplares, cf. G. RIDER, Suse sous les Séleucides et les Parthes, 1965, n90, lám. 9; $n^{\circ}$ 101, lám. 10; $n^{0} 135$, lám. 13; $n^{\circ} 162$, lám. 16; $n^{\circ}$ 348,380 y 381 , láms. $33-35$.

5 Cf. F. Canciani, Riflessioni preliminari sull'iconografia di luppiter, Xenia Antiqua 4, 1995 , 33-40; LIMC VIII, Zeus, Zeus (in peripheria orientali), Zeus/luppiter, Zeus/ luppiter (in peripheria occidentali).

6 D. Fernandez Galiano, Cadmo y Harmonia: imagen, mito y arqueología, JRA 5, 1992, 162 ss.; J. L. Roro, La villa tardorromana de La Malena en Azuara y el mosaico de las Bodas de Cadmo y Harmonia, JRA 5, 1992, 149 y ss.

J. LASSUS, Réflexions sur la technique de la mosaïque, 1957, 26, fig. 19; K. M. D. DUNBABIN, The mosaics of Roman Nort Africa, Oxford 1978, 42, 267, n 1; O. WATTEL-De CROIZANT, Les mosaïques representant le mythe d'Europe (ler Vie siècles). Evolution et interprétation des modèles grecs en milieu romain, Paris 1995, 217-219, lám. XXIX-a. 
y a sus pies el águila; o en los ejemplares de Dánae procedentes de Itálica (Sevilla), de la segunda mitad del siglo II, conservado en la colección de la Condesa de Lebrija ${ }^{8}$, y de la Casa de los Caballos de Cartago, datado ca. $300^{\circ}$, en ambos aparece el busto de Júpiter en la parte superior de la composición. Así como los mosaicos en los que está configurando una de las divinidades planetarias, tema exclusivo del arte romano, representado en los mosaicos de Itálica, del siglo II ${ }^{10}$ Ostia $^{11}$, Bir Chana (Túnez) ${ }^{12}$ o el de la villa de Orbe-Boscéaz (Suiza), todos ellos datados en el siglo III ${ }^{13}$. En este último pavimento aparece el águila llevando sentado a Júpiter con el rayo y el cetro (Fig. 3), tipo iconográfico que se repite en algunas gemas greco-romanas ${ }^{14}$, y que será adoptado para la consecratio del emperador difunto ${ }^{15}$, cuyo texto fundamental se encuentra en Herodiano (IV 2, 1-11) que describe las exequiae del emperador Septimio Severo ${ }^{16}$.

La figura del águila con las alas explayadas no es desconocida en los mosaicos romanos, la encontramos representada en el pavimento de Constantina (Argelia), la antigua Cirta, fechado por K.M.D. Dunbabin a finales del siglo I o comienzos del II ${ }^{17}$, El mosaico de forma rectangular está dividido en tres paneles; en el central aparece el águila en el interior

8 A. Blanco, Mosaicos romanos de Itálica, CMRE II, Madrid 1978, 25-26, nº 1, láms. 1 y 3b; O. WATtEl-De Croizant, La représentation des amours de Jupiter sur une mosaïque d'italica, Annales de Bretagne et des Pays et de l'Ouest 81,2, 1974, 285- 299; G. LóPEZ MONTEAGUdO, EI mito de Perseo en los mosaicos romanos. Particularidades hispanas, Espacio, Tiempo y Forma 11 , Serie II, 1998, 435 y ss., fig. 1.

9 J. W. SAlOMONSON, La mosaïque aux chevaux de l'Antiquarium de Carthage, Le Haye 1965, 67 y 120, n² 48, fig. 52, lám. XLVIII; G. López MonTEAGUdo, op. cit. nota 8, 435 y ss., fig. 3.

10 J. M. Luzón, Arte hispalense. La ltálica de Adriano, Sevilla 1975, 98-99; A. Blanco, Historia de España, España romana, Madrid 1983, 694- 695; J. M. BLÁZQUEZ et alii, La mitología en los mosaicos hispanos-romanos, AEspA 59, 1986, 126, fig. 44; M. P. SAN Nicolás PEDRAz, Iconografía de Venus en los mosaicos hispanos, VI Coloquio Inter. sobre Mosaico Antiguo (Palencia-Mérida 1990), Guadalajara 1994, 404, fig. 12 (presidido por el busto de Venus rodeado de los seis dioses de los planetas y los dias de la semana).

11 G. BecattI, Scavi di Ostia II, I Mitrei, 1954, 47-51, 95, láms. 8 y 21, fig. 20.

12 P. Gaucler, Inventaire des mosaïques de la Gaule et de l'Afrique, II. Afrique Proconsulaire (Tunisie), Paris 1910, n̊ 447; M. YACOUB, Le Musée du Bardo, Túnez 1982, 76; K.M.D. DUNBABIN, op. cit. nota 7, 249, lám. 162.

13 V. vON GONZENBACH, Die römischen Mosaiken der Schweiz, Basilea 1961, 184, lám. 60- 77; La villa gallo-romanine d'Orbe-Boscéaux et ses mosaïques. Guides archéologiques de la Suisse, Orbe 1997, 38-40, fig. 47; W. DRACK y R. FelLMANN, Die Römer in der Schweiz, 1998, lám. 6.

14 LIMC VIII, Zeus, $n^{2} 408-410$.

15 LIMC VIII, Zeus/ luppiter, $\mathrm{n}^{2} 52-55$

16 Sobre los funerales imperiales, cf. J. C. RICHARD, Recherches sur certains aspects du culte imperial: les funerailles des empereurs Romains aux deux premieres siécles de notre ère, ANRW II.16.1. 1980, 1121-1134.

17 K. M. D. DunbabiN, op. cit., nota 7, 255-256. En Hispania también aparece en un mosaico de las Termas de los Arcos I de Clonia, de la primera mitad del s. II, el águila aparece encima de un pedestal mirando a la derecha. C.F. G. LOPEZ MONTEAGUDo et alii, Mosaicos romanos de Burgos, CMRE XII, Madrid 1998, 77-79, lám. 49, n² 26. 


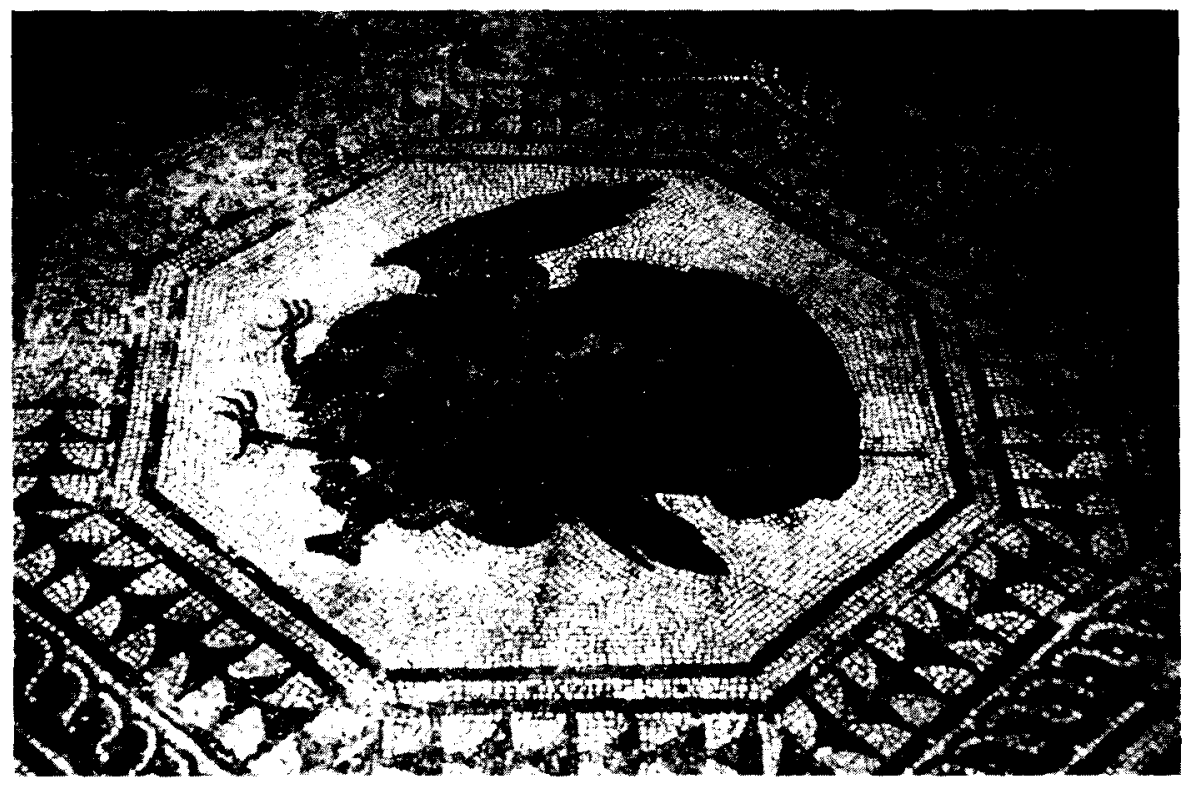

Figura 3. Mosaico de la villa de Orbe-Boscéaz.

de un círculo en torno al cual se desarrolla un esquema compositivo de triángulos curvilíneos en blanco y negro (Fig. 4). En el panel de arriba dos proas afrontadas de barcos cargados con armas; el de abajo dos nadadores afrontados. M.H. Fantar ${ }^{18}$ cree que este pavimento decoraría la casa de uno de los mercenarios de Sittius o del mismo jefe, y relaciona los barcos de guerra y el águila con la destrucción de la flota de Scipion en el puerto de Hippona, que pone fin, en junio del 46 a.C., a la resistencia republicana en la provincia de Africa, anexionándola Julio César al Imperio Romano. De esta forma el mosaico de Constantina sería uno de los pavimentos más antiguos de Africa, compartiendo con otros mosaicos de Pompeya, de la misma fecha, idéntica composición. Con este significado de alusión a la victoria y de apoteosis imperial, se utiliza el águila en numerosos relieves y esculturas romanas, baste recordar el gran monumento del Museo del Prado, procedente de la Frattochie, cerca de la Via Appia de Roma, denominado tradicionalmente "apoteosis de Claudio" ${ }^{19}$,

\footnotetext{
18 M. H. Fantar, La mosaíque en Tunisie, Paris 1994, 20 con fig.

sa Hasta el siglo XVIII existía, encima del águila, un busto que se ha supuesto que pertenecía al emperador Claudio, cf. B. BARRON, Catálogo de la escultura (Museo del Prado), Madrid 1908, 163-164, n²25, lám. LXXV; A. Bı AnCO. Museo del Prado. Catálogo de la Escultura, Madrid 1981. $110-111, n^{\circ} 225$, lám. 15
} 


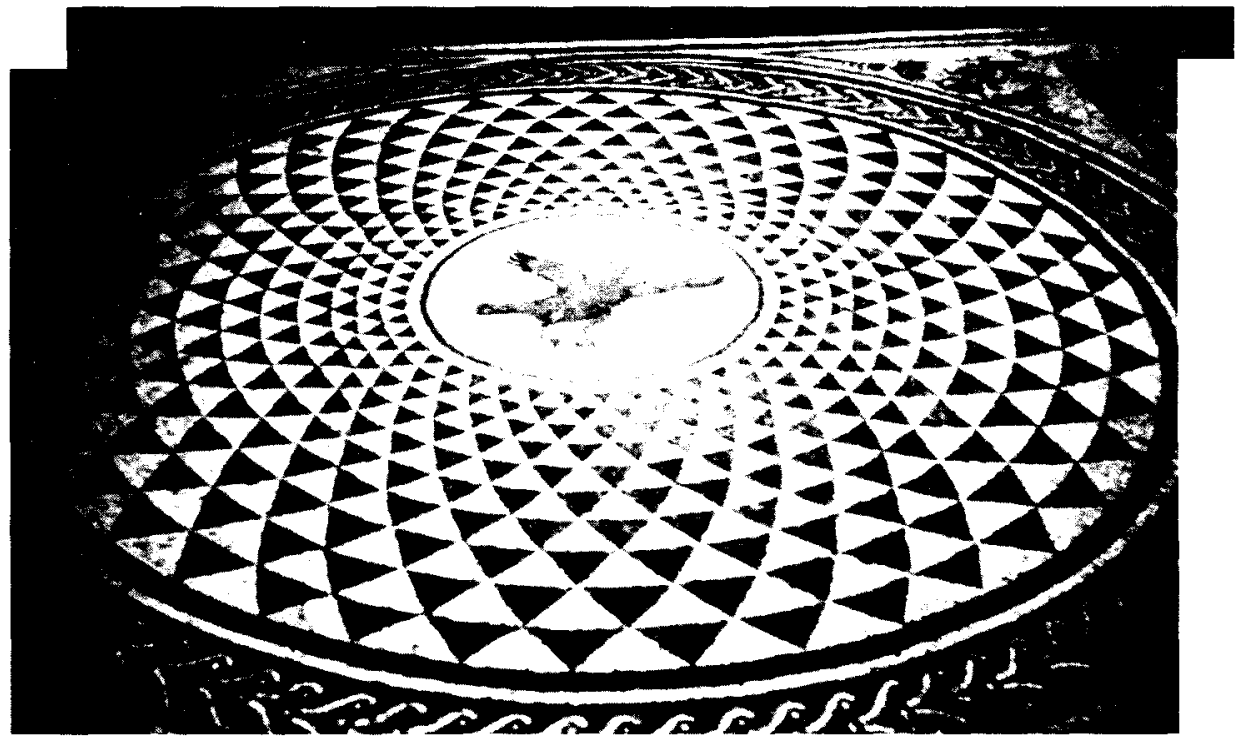

Figura 4. Mosaico de Constantina

en el que se representa el águila con las alas abiertas sobre armas y proas de navíos, sujetando con sus garras el rayo y el globo terrestre (Fig. 5).

Con distinto simbolismo, aludiendo a una idea de inmortalidad, el águila pasa a decorar los pavimentos de época paleocristiana y bizantina. Así, el águila aparece en dos ejemplares de Cirene (Libia), de época de Justiniano ${ }^{20}$, en el primero está representada dentro de un roleo de vid formando parte de la orla del mosaico del ábside de la Iglesia Este de Apollonia (Fig. 6); el otro en un panel cuadrado de la nave de la catedral de Göreme, pero aquí el ave se encuentra, a diferencia de las anteriores, en el momento inmediato de posarse en el suelo (Fig. 7).

El tipo de águila con las alas explayadas aparece también en el mosaico de la Iglesia de Ghiné en el Líbano. fechado a finales del siglo $\mathrm{V}$ o comienzos del VI ${ }^{21}$, ostenta un esquema compositivo a base de cuadrados y rombos y en el centro, dentro de un círculo, se ha figurado

E. Altol di-Rostnbaum y J. Ward-PEfkins, Justiniani Mosaic Pavements in Cyrenaican Churches, Roma 1980, p. 83, lám 2.2: p. 102, lám. 22.2.

M. Cht HAB, Mosaiques du Liban, Bull. Mus.Beyrouth 14-15, 1958-1959. 147-148, lam. XCVIII. 


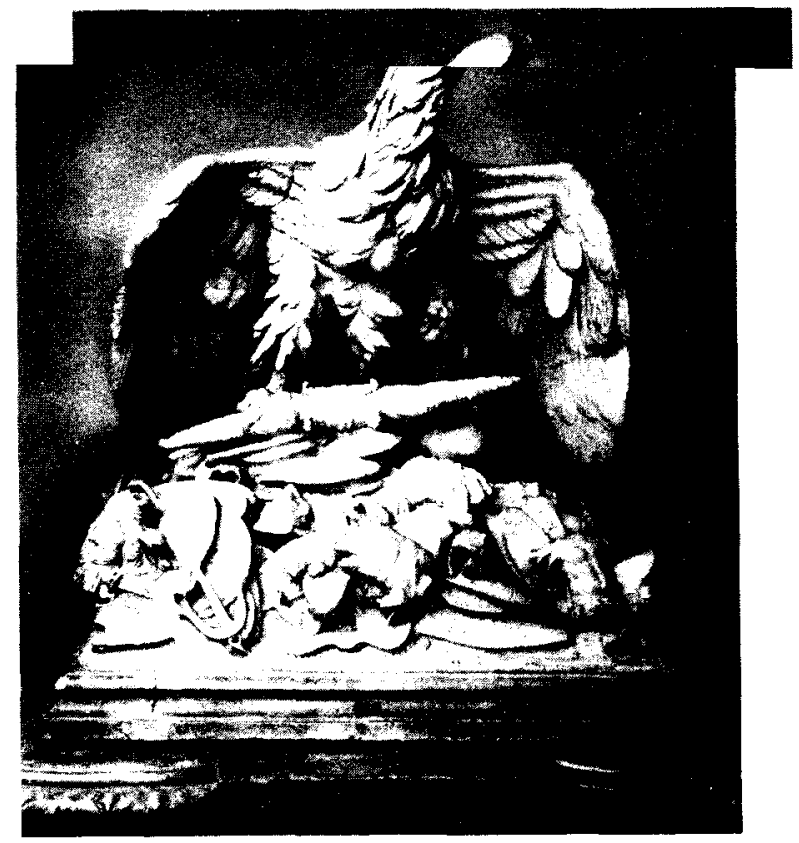

Figura 5. Escultura de la "apoteosis de Claudio". Museo del Prado. Madrid. (Foto ML. Tarraga. CSIC).

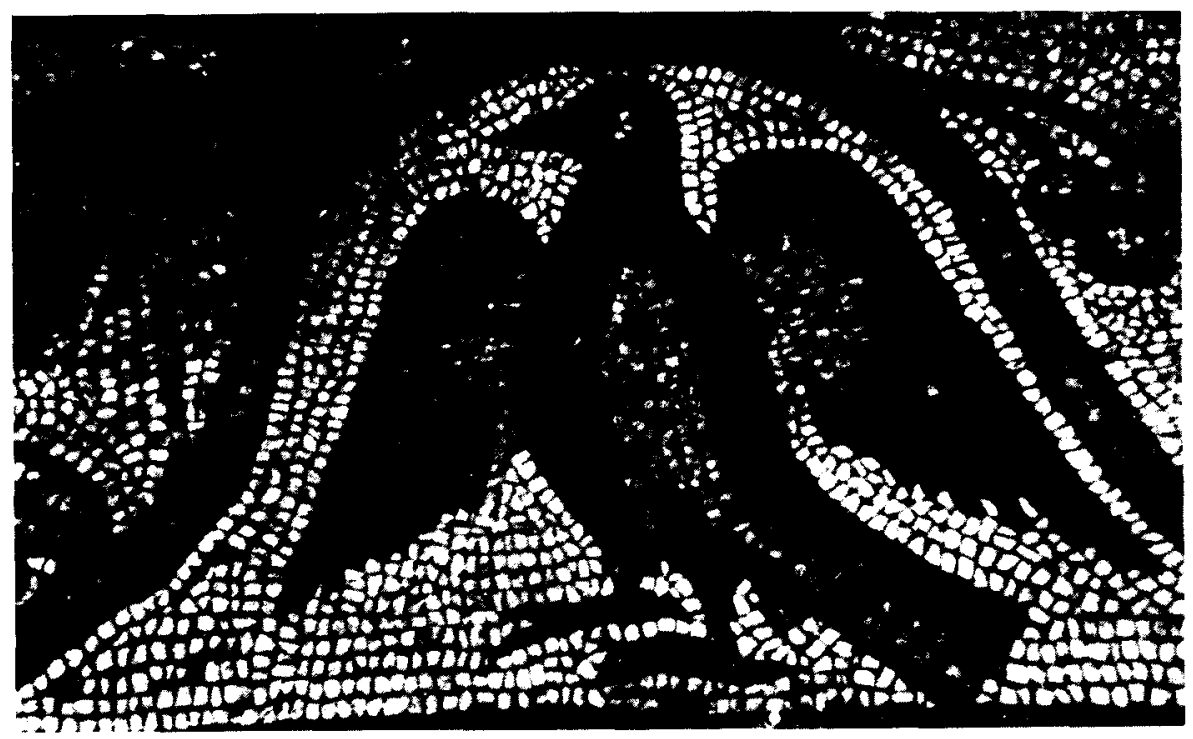

Figura 6. Mosaico de la Iglesia de Apollonia. Cirene. 


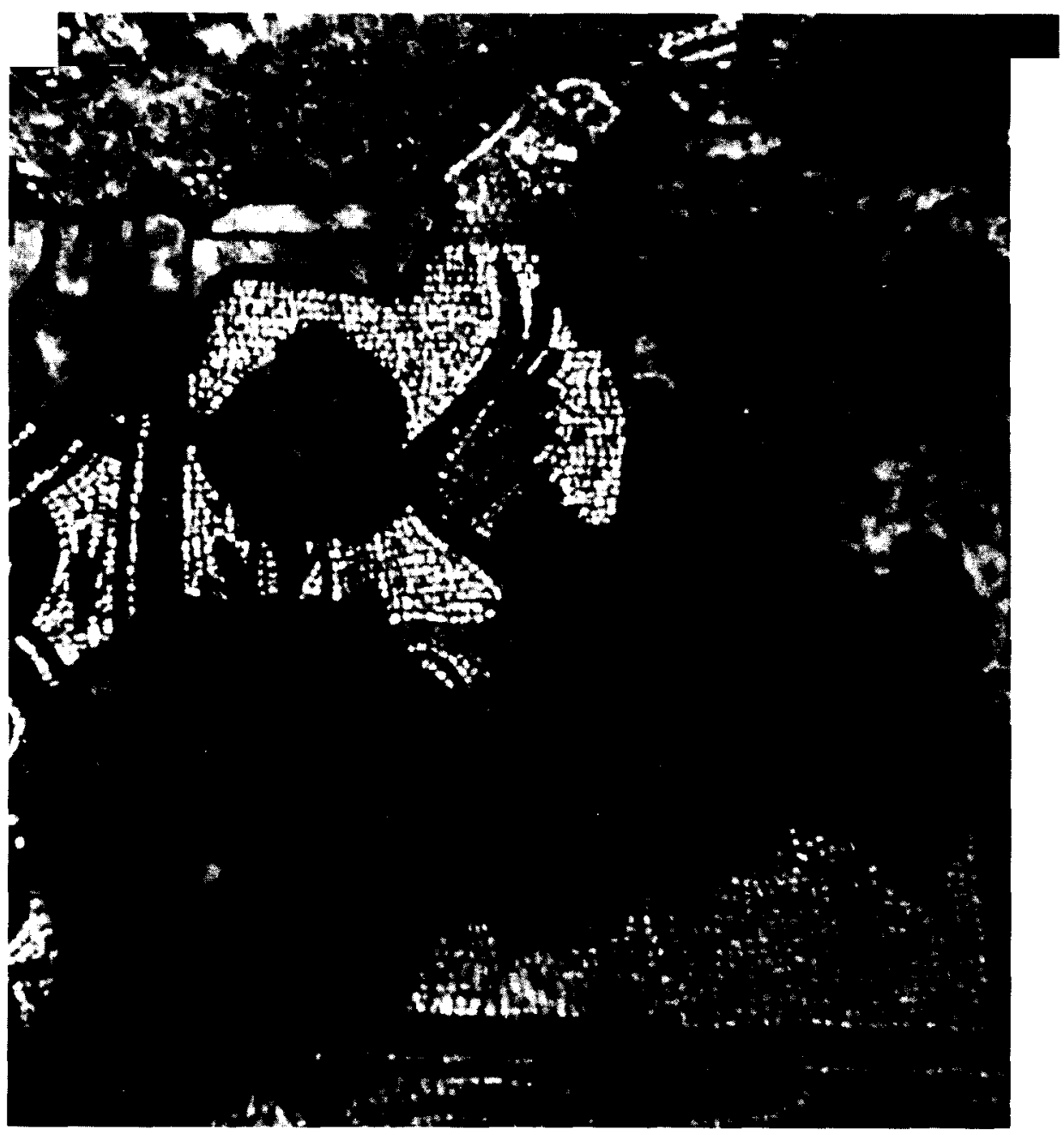

Figura 7. Mosaico de la Catedral de Göreme. Cirene.

majestuosamente el animal emblemático (Fig. 8), como en Córdoba y Cirta. Con la misma iconografía se representa el águila en un pavimento conservado en el Museo de Manisa (Turquía) ${ }^{22}$, aunque con distinta

fig. 14.

J. M. Blazouez y G. Lopez Monteagudo. Mosaicos de Asia Menor, Aespa 59, 1986, 240. 
composición y decoración. En el círculo central se encuentra el ave, ro-

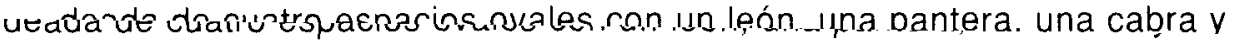
un ciervo; otros espacios geométricos están ocupados por varios animales y monstruos marinos (Fig. 9).

La musivaria griega ha proporcionado otro ejemplar de este tipo en la basílica de Delfos, datado a finales del siglo $\mathrm{V}$ o principios del $\mathrm{VI}{ }^{23}$, con un esquema compositivo muy similar al anterior, donde el águila ocupa los cuatro espacios hexagonales en torno al medallón central en el que

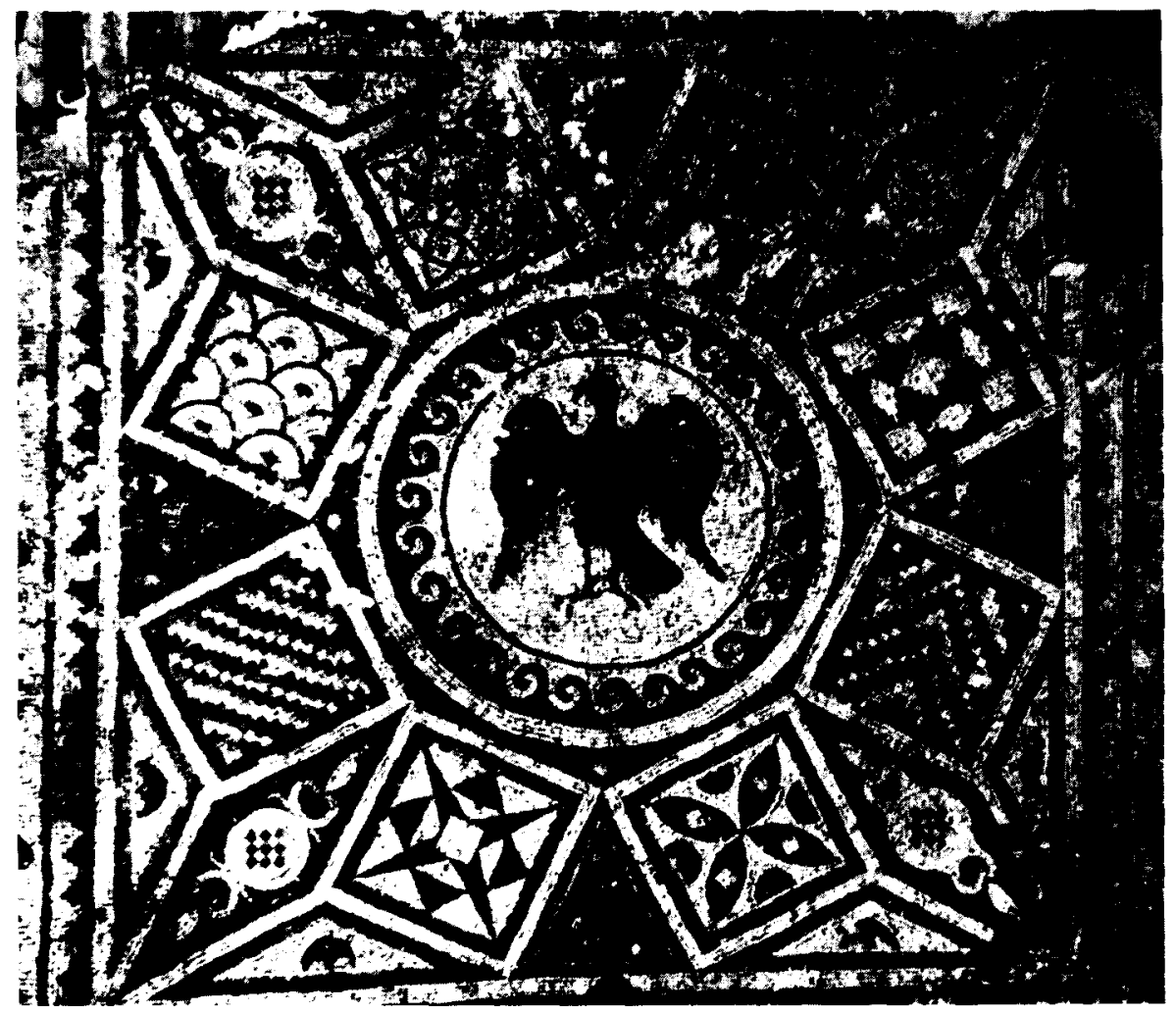

Figura 8. Mosaico de la lgesia de Ghiné. Libano.

M. Splro, Critical Corpus of the Mosaics Pavements on the Greek Mainland. Fourth/Sixth Centuries with Architectural Survys, Nueva York 1978, 229 y ss., láms. 258-260; Corpus Mosaicorum Christianorum Vetustiorum Pavimentorum Graecorum, Byzantina Mnhmeia 7, $t$ II, Tesalonica 1987, 195, lám. 343a 


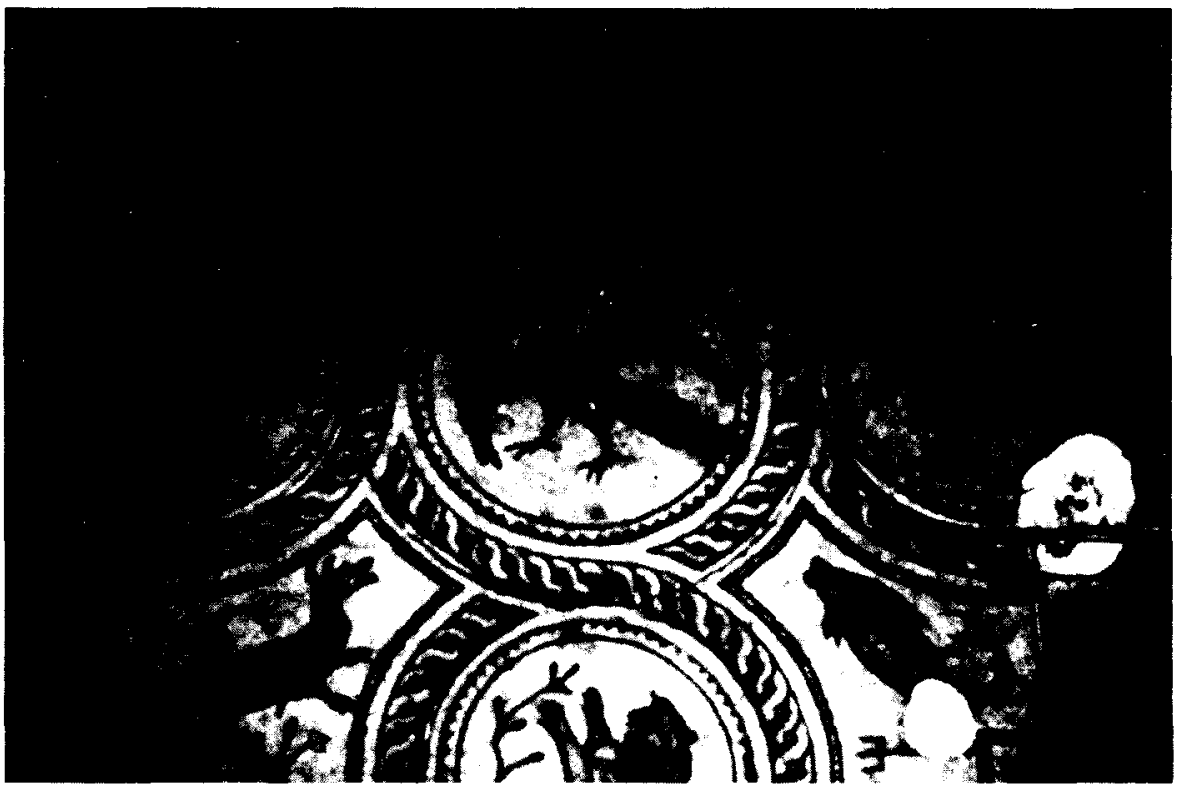

Figura 9. Mosaico del Museo de Manisa

se ha representado una escena de caza, un felino atacando a un ciervo (Fig. 10).

Sin embargo, el paralelo más próximo para la iconografía del mosaico cordobés, lo encontramos en una lucerna de Brugg que se conserva en el Museo de Vindonisa (Suiza) ${ }^{24}$, en donde el águila sobre el globo ocupa todo el disco con la alas desplegadas y llevando en sus garras el rayo (Fig. 11).

Por consiguiente, creemos que el motivo representado en el pavimento hispano, al igual que el de la lucerna sería una alusión a Júpiter, dios por excelencia del panteón romano, por medio de dos de sus atributos clásicos, el águila y el globo terráqueo.

En cuanto a las aves que rodean el medallón central constituyen un motivo frecuente en la decoración de numerosos mosaicos romanos de Italia, Africa, Bizancio, etc., y en particular en los hispanos. Baste recordar

A. Lf irundogut, Die röm. Lampen in der Schweiz, Mainz Am Rheim 1977, 143 motiv. 58 218, n 146. lám. 28. LIMC VIII. "Zeus/ luppiter (in peripheria occidentali)". $n^{\circ} 48$. 


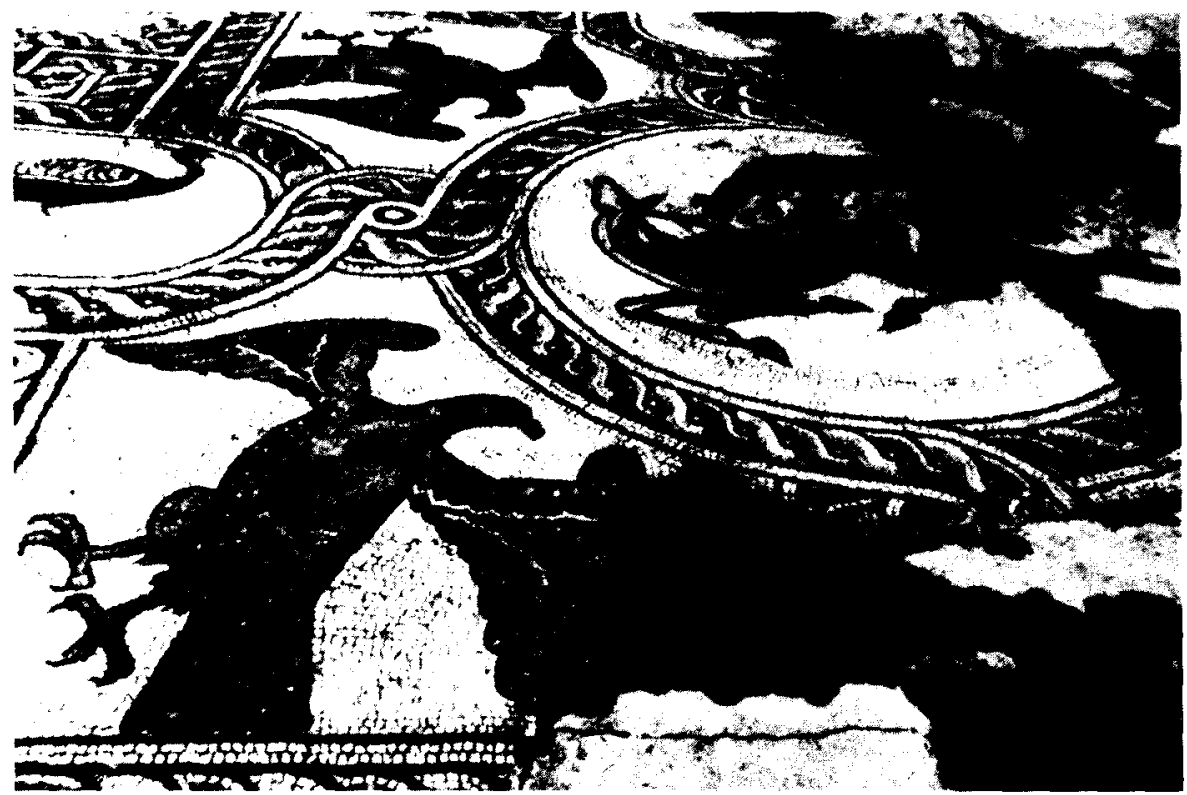

Figura 10. Mosaico de Delfos.

los dos pavimentos italicenses de la Casa de los Pájaros ${ }^{25}$ y el mosaico del Nacimiento de Venus de Cártama (Málaga) ${ }^{26}$, fechados la segunda mitad del siglo II, así como el pavimento burgalés de Sasamón, de fines del siglo II o principios del III ${ }^{27}$ o el mosaico de los pájaros de Beas del Segura (Jaén), del siglo IV ${ }^{28}$.

La cronología del mosaico oscilaría, teniendo en cuenta la fecha que se sitúa el conjunto de los pavimentos mitológicos de la Colonia Patricia Corduba ${ }^{29}$ en los siglos II y III.

A. Garcia y Bthliloo, Colonia Aelia Augusta ltalica. Madrid 1979, 13 y 132, lams VIll- IX: M. Duran. IConogratia de los Mosaicos Romanos en la Hispania alto-imperial. Barcelona 1993. 51-54. $n \div 5$, lám. IIl.

J. M. Bi azolut Z, Mosaicos romanos de Cordoba, Jaén y Málaga, CMRE III, Madrid 1981. 85-88, n-61, láms. 70. 92-93: M. P. SAN NiCOIAS PEufial. op. cit., nota 10, 393, fig. 1

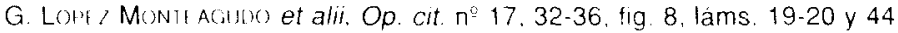

J. M. BLAlult: et alii. Hallazgo de mosaicos romanos en Beas de Segura. AEspA. 59. 1986 , 227-230. con abundantes paralelos de mosaico con repressentación de pájaros dentro de recuadros o círculos.

J. M. B। aroun /. op. cit., nota 26, 13-50 


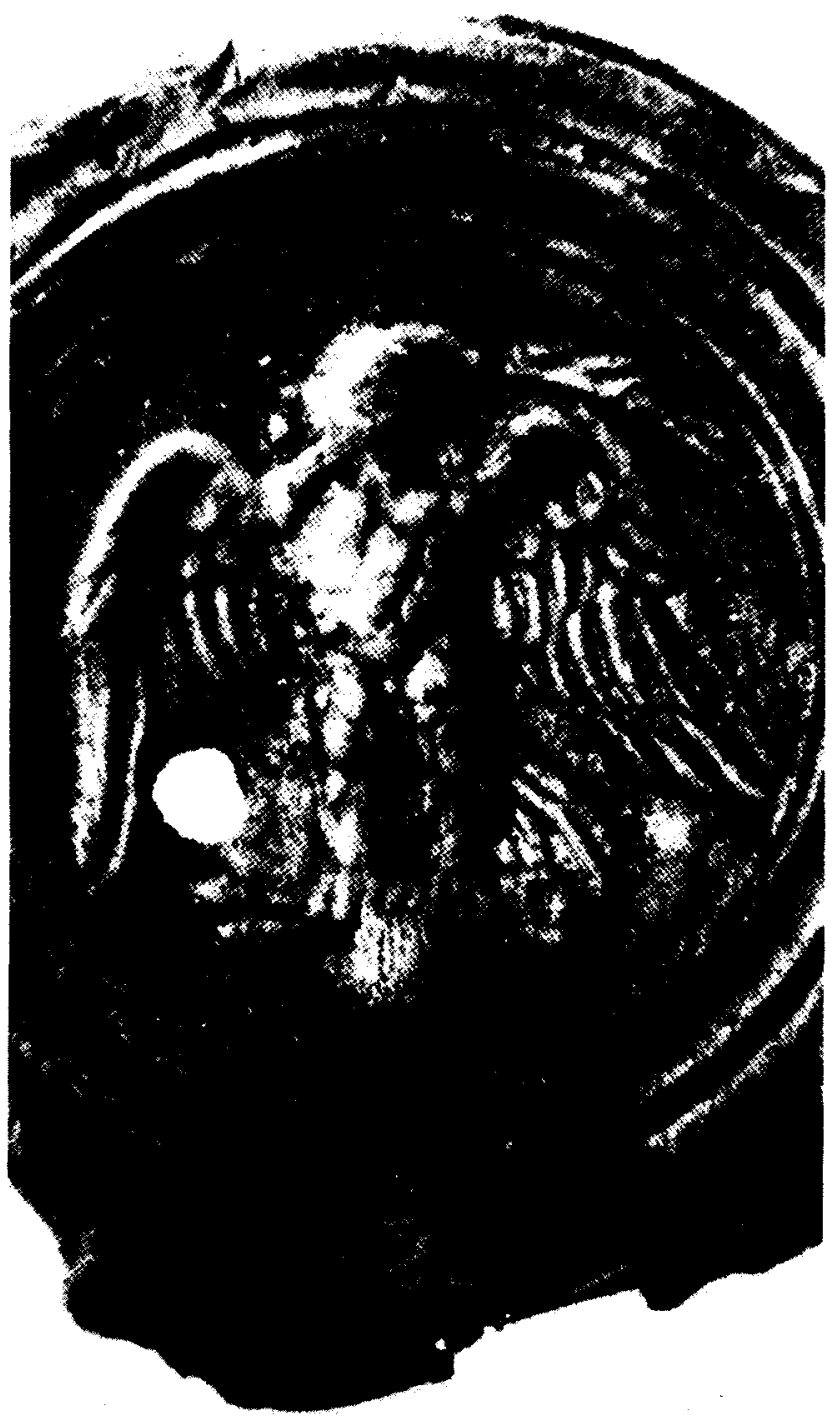

Figura 11. Lucerna de Brugg. Museo de Vindonisa. 


\section{Recensiones}

